ISSN: 0212-0267

DOI: http://dx.doi.org/IO.I420I/hedu20I6353934I2

\title{
FRANCISCO DE FRUTOS. MAESTRO DE PRIMERAS LETRAS PURIFICADO. SEGOVIA I823
}

\section{Francisco de Frutos. Teacher of the first letters purified. Segovia I823}

José Luis Manrique SANZ

Universidad de Valladolid

Correo-e: manriquin@yahoo.es

Recepción: I de marzo de 20I5. Envío a informantes: is de marzo de 2015.

Fecha de aceptación definitiva: 9 de mayo de 2016

Resumen: La importancia de la ciudad de Segovia como centro de producción de paños en el siglo Xvi dejó paso en siglos posteriores a una lenta y profunda decadencia. Sin embargo, a mediados del siglo xviII, el fabricante de paños e ilustrado D. Diego Ochoa de Hondategui dejó toda su fortuna, casi 4 millones de reales, destinada a obras pías y educativas. Un colegio para niños pobres y huérfanos y una escuela de primeras letras fue el lugar donde transcurrió la vida docente del maestro Francisco de Frutos Illanas. Obligado durante el trienio constitucional a enseñar el Catecismo Político de la Constitución española de i8ı2, a la vuelta de Fernando VII en 1823 , primero fue tenido por «negro» y después purificado.

Palabras Clave: Maestro; primeras letras; gratuidad; purificación; educación; escuela.

AвSTRACT: The importance of the city of Segovia like center of production of cloths in the r6th century opened way in the centuries later to a slow and deep decadence. Nevertheless, in the middle of the i8th century, the manufacturer of cloths and illustrated D. Diego Ochoa de Hondategui it left all his fortune, almost 4 millions of royal, destined for pious and educational works. A college for poor and orphan children and a school of the first letters, was the place where there passed the educational life of the teacher Francisco of Fruits Illanas. Forced during 
the constitutional triennium, to teaching the Political Catechism of the Spanish Constitution of I8I2, to the return of Fernando VII in I823, first it was had as «black» and later purified.

KEY WORDS: Teacher; the first letters; gratuitousness; purification; education; school.

\section{Contexto histórico}

$\mathrm{L}$

A CIUDAd DE SEgovia, uno de los centros manufactureros más importantes de España y de Europa en el siglo Xvi, especializada en la producción de paños de calidad, los conocidos como Segovias, no era a finales del siglo XVIII y principios del xix lo que había sido, ni volvería a serlo.

Se había producido un gran descenso demográfico. Los 2I.2I3 habitantes que cataloga García Sanz en el año I59i habían pasado a II.203 en el año 1787. La principal causa de este descenso demográfico hay que buscarla en las importantes crisis de mortalidad catastrófica que se dieron a finales del siglo Xvi, casi todas a consecuencia de las malas cosechas y consecuentemente de la escasez de alimentos. En la peste bubónica del verano de 1599 muere aproximadamente el i $8 \%$ de la población de la ciudad, una estimación más fiable que los i2.00o muertos que contabiliza Colmenares ${ }^{2}$, que habrían causado la despoblación de Segovia.

En el siglo XVII comienza un largo periodo de decadencia en el que la ciudad se estanca, se ruraliza, se empobrece. Martínez de Pisón cita al viajero François Bertaut que había visitado la ciudad en 1659 y decía que «... la ciudad está casi desierta y pobre. Una señal de su pobreza... es que... a eso de las dos de la tarde no había habido pan en toda la ciudad y no se sorprendían de ello... y la mayor parte no piensan más que en vivir al día...»3. Sin embargo, esta situación no era igual para todos los habitantes, «... no hay que confundir su ruina industrial y su postración social con un cese de la prosperidad de sus grupos dirigentes amos de campos y ganados»4.

La fama de los internacionales paños segovianos, la trashumancia ligada a los numerosos esquileos serranos, la gloria de la cabaña merina principia a ser historia, a pesar de la aparición de algunos personajes importantes para la ciudad, entre los que se encontraba D. Diego Ochoa de Hondategui «fabricante de paños, ganadero mesteño y exportador de lanas finas», tal y como le describía García Sanz. La economía castellana y especialmente la de Segovia en el siglo XVIII era predominantemente rural, ocupaba al 91,45\% de la población. Se mantenían,

- García Sanz, A.: Desarrollo y crisis del Antiguo Régimen en Castilla la Vieja: economía y sociedad en tierras de Segovia de I500 a I8I4, Madrid, Ed. Akal Universitaria, I986, p. 45.

2 De Colmenares, D.: Historia de la insigne ciudad de Segovia y compendio de las historias de Castilla, II, Segovia, Academia de Historia y Arte de San Quirce, 1984, p. 366.

3 Martínez de Pisón, E.: Segovia: evolución de un paisaje urbano, Madrid, Colegio de Ingenieros de Caminos, Canales y Puertos, 1976, p. 153 .

4 Martínez de Pisón, E.: op.cit., 1976, p. I49. 
rígidamente los estamentos clásicos, nobleza y regidores, clero y pueblo llano. Había burguesía, sí, poderosa económicamente que intentaba por todos los medios acceder a las posiciones de poder, incluso a la nobleza, a ser regidores en el Ayuntamiento, pero eran tantas las trabas que, al final, sólo imitaban a la nobleza poseedora de tierras y ganados. Al igual que ellos, querían estar cerca de Segovia, pero pasaban sus días en la Corte, en Madrid. Quizá allí pudieran medrar, conseguir una posición social más acorde con el capital que poseían.

Si la imagen de Segovia en el XVIII era decadente, la información que existe sobre el siglo xIx es verdaderamente desoladora. En general, como dice Martínez de Pisón, todo son «... lástimas y lamentos...»: malos caminos, comercio sólo de importación por falta de recursos, lo que ocasionaba la carestía de los precios, escasa población, deficiente enseñanza, calles tortuosas y en mal estado, casas viejas, carencia de alumbrado, en fin, pobreza generalizada. «El siglo XIX segoviano es un siglo de penurias, pero también fue un siglo de quejumbres»s.

En definitiva, nos encontramos en una ciudad excesivamente ruralizada, una capital «campesina», habitada por aldeanos y labradores principalmente en los arrabales, una pequeña población en la que las actividades artesanales y fabriles disminuían a marchas forzadas mientras las clases dirigentes continuaban acumulando riqueza en ganados y en rentas del campo, incrementándolas con la compra de tierras de pasto... hasta la Guerra de la Independencia. Después de ella todo continuó igual. El mismo orden, la misma apatía y decadencia.

\section{Contexto educativo}

En los siglos XVII y XVIII dependiendo de su fundación y de sus características, se podían encontrar gran variedad de escuelas elementales. Las había parroquiales, municipales, de las Doctrinas, públicas, diocesanas, caritativas, de huérfanos, de huérfanas, de amiga, de hospital, de órdenes religiosas, de fundación real, particulares.

Del mismo modo, se podía hablar de varios tipos de maestro. Estaban los que atendían a la nobleza o a la burguesía; el que desarrollaba sus actividades en un aula pública, ya fuese financiada por diversas instituciones o bien mediante el desempeño de una actividad libre y remunerada, y también el maestro regio que enseñaba a los príncipes.

Cuando se les examinaba para el oficio de maestro, a veces por el cura del pueblo, siempre era de las mismas e imprescindibles materias: doctrina cristiana, lectura, tablas de aritmética, conocer y escribir algún o algunos tipos de letra (el maestro era a veces el secretario del municipio o fiel de hechos o escribano), e incluso, a veces, que supieran cantar, con el fin de hacer las veces de sacristanes en las iglesias.

Estas mismas materias de las que eran examinados eran las que tenían que enseñar a sus alumnos, la doctrina cristiana, con las principales oraciones, tal y

Martínez de Pisón, E.: op.cit., 1976, p. 222. 
como especificaba la Cartilla de Valladolid 6 ; el aprendizaje de la lectura a través de cartillas individuales o catecismos de pequeños formatos, con el mismo método que se seguía en toda Europa, el método silábico, con sus tres fases, las letras, la sílaba y la palabra7. El aprendizaje de la escritura (los maestros solían ser magníficos calígrafos e ilustradores $)^{8}$. También en esta clase se les enseñaba a cortar las plumas, a hacer tinta con los materiales adecuados y a copiar, normalmente mediante muestras, y por último las cuentas.

La llegada de los ilustrados a España con Carlos III jugó un papel importante en el campo de la educación, ya que pensaban que gracias a la instrucción, a la educación de la Juventud, los Estados lograrían la mejora en todos los campos, industria, comercio... aunque verdaderamente la educación no estaba pensada para todos los estamentos. Sí que había que tener unos conocimientos imprescindibles, contar, leer, escribir, la doctrina cristiana... todo lo necesario para poder desempeñar un oficio de manera profesional. En cuanto a los estudios superiores a la enseñanza de las primeras letras, ya era harina de otro costal.

A pesar de todo, era mayoritariamente tenida en cuenta la opinión de Jovellanos respecto al pueblo, «la felicidad era una consecuencia de su instrucción»?.

Los gobernantes creían que España necesitaba una educación uniforme y patriótica, controlada por el Estado. Sólo el Estado, ante el atraso generalizado, era capaz de llevar a cabo semejante empresa. Todos no opinaban así. Para algunos ilustrados, destinar a la educación y a la instrucción popular tantos recursos haría que disminuyese el número de jornaleros y de trabajadores dedicados a la industria, razón por la que la educación se debería dejar en manos de la iniciativa privada. También es cierto que no había dinero suficiente ni en el propio Estado ni en los ayuntamientos de ciudades y pueblos para poder hacerlo. De tal manera

6 Resines Llorente, L.: La Catedral de papel. Historia de las Cartillas de Valladolid, Valladolid, Diputación de Valladolid, 2007. La Catedral de Valladolid tenía el Privilegio Real para imprimir y vender las cartillas en las que los niños aprendían a leer desde el año 1583 , privilegio que se fue renovando cada cierto tiempo. En las que se imprimieron a partir de I790, acordes a la época ilustrada, aparecen nuevos contenidos, aunque el que permanece inalterable es el aprendizaje de la Doctrina Cristiana.

La Sociedad Económica Segoviana de Amigos del País presentó en 1784 el Plan del Método y Reglas que deverá observarse para aprender a leer, escrivir y contar (Archivo Municipal de Segovia - AMS II-220) con el que pretendía intervenir en las escuelas de primeras letras de la capital. En él, se especificaba la forma de ascender de clase. En la de leer, primero había que saber el abecedario y silabario, con letras mayúsculas incluidas, después aprender a deletrear, a continuación leer de corrido comprendiendo el sentido de las frases y oraciones y por último leer procesos y cartas manuscritas. Además ponían cartelones en las paredes con imágenes del abecedario, sílabas y signos de puntuación que debían aprender y recitar de forma repetitiva. La clase de escribir la dividían en: de palotes, gordo y delgado. Finalmente estaba la clase de contar, en la que se aprendía a sumar, restar, multiplicar, partir con un número, partir por entero y reducir de maravedises a reales y viceversa.

${ }_{8}$ El maestro de escribir de las escuelas del Patronato de Hondategui, D. Domingo Sáez Montejo, es citado por D. Torquato Torio de la Riva como «buen calígrafo» en dos de sus libros, El arte de escribir por reglas y también en Ortología y Diálogos de Caligrafía, Aritmética, Gramática y Ortografía Castellana (Madrid, Imprenta de Ibarra, I8I8).

9 Jovellanos, G.: Memoria sobre educación pública. Su tratado teórico-práctico de enseñanza con aplicación a las escuelas y colegios de niños, Madrid, BAE, I858, pp. 230-23I. 
que dejaron la educación popular, la instrucción de los jóvenes, de los niños, en manos de la Iglesia, principalmente en manos de los escolapios por ser la única orden religiosa que se dedica exclusivamente a la enseñanza, y también porque sería la más económica para las arcas del Estado.

Para poder establecer escuela, quienes pedían la apertura del centro tenían que facilitar: una iglesia amueblada, un edificio para el colegio, vivienda para los escolapios, una biblioteca y una huerta. No se pedía salario para los maestros, sólo ayudas económicas espontáneas para el sustento de los escolapios. Las Escuelas Pías se comprometían a facilitar un director, un confesor, un horario y reglamento escolar, examen de ingreso en el centro para colocar al alumno en su grado correspondiente, exámenes para que los alumnos puedan pasar de grado a un curso superior, uniformidad y homogeneidad en la enseñanza de todos los centros y también distintos maestros, según la diversidad, número y capacidad de los oyentes ${ }^{\text {ro }}$.

Este modelo de las Escuelas Pías fue imitado por muchas escuelas, públicas y privadas, principalmente en lo referente a la organización de sus clases, de sus enseñanzas, sus métodos uniformes y, sobre todo, lo que importaba a los ruinosos ayuntamientos españoles, su gratuidad.

El escolapio segoviano Felipe Scio plasmó este modelo de educación en el Método Uniforme para las Escuelas (1780) ${ }^{\mathrm{II}}$ y este método permaneció casi inalterable en el tiempo incluso después de la Guerra de la Independencia.

\section{El Patronato de fundaciones de D. Diego Ochoa de Hondategui}

El i4 de agosto de i75r fallecía el fabricante de paños e ilustrado segoviano D. Diego Ochoa de Hondategui.

Sin descendencia, en su último testamento dejó instituido un Patronato de fundaciones, formado por el padre guardián del convento de San Francisco; el cura párroco de la iglesia del Salvador, y dos fabricantes de paños, D. Juan de Arróniz y Velasco y D. Antonio Sacristán ${ }^{12}$.

Cuando se realizó el inventario y tasación de sus bienes «por personas inteligentes» su patrimonio fue valorado en cerca de 3.500.000 reales de vellón.

Una casa esquileo, un molino de papel, varias viviendas en la ciudad, una numerosa cabaña lanar merina... todos los bienes y rentas que generaban tuvieron una única finalidad: el sostenimiento de unas fundaciones, unas de tipo piadoso y

1o Faubell Zapata, V.: «Los Escolapios en España», Analecta Calasanctiana, n. ${ }^{\circ} 99$ (2008), pp. 57-65.

II Sin tener en cuenta el Primitivo Reglamento Escolar de I72I, hay publicados cuatro métodos uniformes para las escuelas pías: Método fijo, para los colegios de Aragón y Valencia, del año i754; el Método del año 1762, que fue reeditado en 1771; el Método Uniforme para las escuelas, del año 1780, cuyo autor es Felipe Scio, y por último el Método uniforme del año 1796 para la provincia de Cataluña. Según el principio de uniformidad, cuando se decidía el calendario y el horario a seguir, todos los colegios de la demarcación correspondiente debían seguirlo estrictamente.

${ }_{12}$ Archivo Histórico Provincial de Segovia (AHPS), Protocolo 2753, folios 40I-4I9. 
otras de tipo educativo, entre las que se encontraban la creación de unas escuelas de primeras letras (que funcionaban ya desde 1742) y de un colegio para niños huérfanos, edificio que se inauguró el i de enero de 1756 con la entrada de los doce primeros niños pobres, a los que vestía, alojaba, daba de comer y educaba entre los 7 y I4 años ${ }^{13}$. El número de alumnos de las escuelas fue aumentando con el paso de los años hasta llegar casi a la cifra de 200.

Dos maestros, uno de leer y otro de escribir, los mejores pagados de la ciudad, médico, boticario, enfermería, ama de llaves, 4 criadas, un rector del colegio (al principio era el maestro de escribir, pero a partir del año i8oo fue uno de los patronos, el cura de la parroquia del Salvador), la posibilidad de aprender un oficio al término de la escuela costeado por el Patronato, o bien seguir estudiando en las clases de Gramática y Filosofía que tenía instauradas en el convento de San Francisco, también a cargo de las fundaciones de D. Diego Ochoa de Hondategui.

Todas estas cosas hacían que el Colegio y Escuela de Hondategui, más bien que el nombre de Hondategui fuese asociado al término de «enseñanza gratuita», eso sí, sólo para niños, y que muchas instituciones de Segovia, principalmente el Ayuntamiento y desde su creación en 1780 la Sociedad Económica de Amigos del País, intentasen intervenir de alguna u otra forma en la gestión del Patronato, de los millones de reales que tenían, cosa a la que se negaban rotundamente los patronos, un monje, un cura y dos fabricantes de paños.

Con el tiempo, no serían las instituciones segovianas, sino el favorito Godoy quien, con su «desamortización» de los bienes de las obras pías, conseguiría ahogar económicamente al Patronato, que tuvo que vender la mayoría de sus propiedades y el dinero resultante depositarlo en la llamada Caja de Consolidación, la «deuda perpetua», que no les permitió recuperar el principal y tampoco cobrar los intereses prometidos del $3 \%$ anual.

El Estado no tenía fondos. Los que obtuvo no sirvieron de mucho, pero con esta medida logró llevar a la ruina al Patronato.

En los años 1803-I804 se vendieron casi todas las propiedades. Desde ese momento dejó de entrar dinero con regularidad en las arcas del Patronato, lo que repercutió negativamente en la marcha de las escuelas y del colegio. Se redujeron las plazas para los colegiales, se racionaba la comida o se repartían comidas económicas (incluso compraron una cocina económica de Rumfort), se cerraron de forma temporal tanto el colegio como las escuelas, no se pagaba a los maestros ni a los otros empleados e incluso, a veces, el edificio del colegio, uno de los más espaciosos de la ciudad, era ocupado por militares.

En este contexto tan poco favorable, hacia I8I8 necesitaban un nuevo maestro de leer en las escuelas de primeras letras del Patronato de Hondategui. El maestro de

${ }_{13}$ En la actualidad es la sede del IEs Mariano Quintanilla, y desde su inauguración en 1756 (excepto dos periodos cortos de tiempo en que fue ocupado por las tropas francesas en la Guerra de la Independencia y con la llegada de los cien mil hijos de San Luis) siempre ha estado dedicado a la educación, bien con las escuelas de primeras letras, bien siendo la sede del Instituto de Segunda Enseñanza, después Instituto General y Técnico, bien compartiendo espacio las escuelas de primeras letras y el Instituto. 
escribir, Domingo Sáez Montejo, no podía hacerse cargo del numeroso grupo de alumnos matriculados, casi todos gratuitamente, así que los patronos, muy independientes como siempre, decidieron realizar un proceso de selección. Y parece que tenían poco donde elegir.

\section{El maestro de primeras letras Francisco de Frutos Illanas}

Fue nombrado maestro 2. ${ }^{\circ}$ ayudante de la Escuela el I2 de mayo de I8I8 ${ }^{\mathrm{I4}}$, después de que varias personas presentaran la solicitud para la plaza, aunque ninguno de ellos tenía todavía, según los patronos, el «...título de maestro aprobado por el Real y Supremo Consejo de Castilla...». Hubo, siempre según la estimación de los patronos, dos personas mejor preparadas, D. Francisco de Frutos Illanas y D. Pedro Cos, y no decidiéndose en cual debían hacer la elección,

... determinaron que los hiciese la suerte y habiéndose verificado el que estos dos entrasen en cantazo en dos cédulas en que estaban escritos sus nombres y apellidos, sacando una de ellas recayó la suerte de tal Maestro en D. Francisco de Frutos Illanas [...] más con la precisa condición de haber de ser examinado y aprobado para el Magisterio y de presentar el Título de Maestro por el Supremo Consejo de Castilla, como nos lo ofrece en su memorial...

Una vez que estuvo en la escuela, hay numerosas referencias a sus actuaciones, siempre de acuerdo con su compañero el maestro de escribir Montejo, principalmente durante el trienio liberal, ya que desde el Ayuntamiento de Segovia se agilizó la petición de informes y documentos relativos al estado de las escuelas de primeras letras de la capital. El 29 de diciembre de 1820 se realizaba un informe por parte del Ayuntamiento, acerca de las rentas de los Centros de Enseñanza en la capital ${ }^{15}$.

Los establecimientos de enseñanza, sus rentas y de donde provenían éstas, eran los siguientes:

\begin{tabular}{|l|l|c|}
\hline \multicolumn{1}{|c|}{ Establecimiento } & \multicolumn{1}{|c|}{ Procedencia } & Rentas \\
\hline Seminario Conciliar & $\begin{array}{l}\text { Corre a cargo del Obispo y sus rentas de granos } \\
\text { y maravedís deducidos gastos y compras }\end{array}$ & 27.796 reales \\
\hline $\begin{array}{l}\text { Colegio Theologos } \\
\text { de S. Ildefonso }\end{array}$ & $\begin{array}{l}\text { Agregado el todo de sus rentas al pago de 8 be- } \\
\text { cas que debe tener en el referido Seminario }\end{array}$ & I3.484 reales \\
\hline $\begin{array}{l}\text { Colegio de Doctrina } \\
\text { Cristiana, para niños } \\
\text { huérfanos }\end{array}$ & $\begin{array}{l}\text { Sólo hay 3 en el día, un rector y un pasante. Las } \\
\text { rentas consisten en grano que percibe en cillas y } \\
\text { réditos de juros }\end{array}$ & IO.I2I reales \\
\hline
\end{tabular}

${ }_{14}$ Archivo Diocesano de Segovia (ADs), Armario I2, Fundaciones, Capellanías, Cabildos. Libro de Acuerdos, folio 132.

is Archivo Municipal de Segovia (AMs), I199-67. 
FRANCISCO DE FRUTOS. MAESTRO DE PRIMERAS LETRAS PURIFICADO. SEGOVIA I823 JOSÉ LUIS MANRIQUE SANZ

\begin{tabular}{|l|l|r|}
\hline \multicolumn{1}{|c|}{ Establecimiento } & \multicolumn{1}{|c|}{ Procedencia } & Rentas \\
\hline $\begin{array}{l}\text { Colegio de S. Diego. } \\
\text { Ondategui }\end{array}$ & $\begin{array}{l}\text { Las rentas tienen varias aplicaciones, ya de en- } \\
\text { señanza o de beneficencia. En el día consisten } \\
\text { en I48.948 reales y io maravedís en cada año que } \\
\text { debe pagar el crédito público, que está debiendo } \\
\text { a dicho establecimiento 9 anualidades }\end{array}$ & I48.948,Io \\
\hline Noble Junta de Linajes & Productos de varias dehesas y algunos censos & 62.60o reales \\
\hline $\begin{array}{l}\text { Temporalidades } \\
\text { de los exjesuitas }\end{array}$ & $\begin{array}{l}\text { Consisten en granos y otros efectos que se per- } \\
\text { ciben de ciertas cillas de este Obispado, que hoy } \\
\text { percibe el crédito público. Se aplican al pago de } \\
\text { 2 maestros de primeras letras y dos cátedras de } \\
\text { latinidad }\end{array}$ & 23.493 reales \\
\hline
\end{tabular}

TOTAL 286.442,Io reales

Como se puede comprobar, las rentas más numerosas eran las del Patronato de Hondategui, unas rentas que no se cobraban, que dependían de la disposición del Estado, del Crédito Público a abonar los intereses que debían. Si nos limitamos a las rentas de los establecimientos de primeras letras, los Niños de la Doctrina, los antiguos jesuitas y el Patronato de Hondategui, la diferencia es sustancial. Sin embargo, la escuela en la que ejercía Francisco de Frutos Illanas no tenía rentas efectivas.

La llegada del trienio liberal generó un cambio sustancial en la ciudad de Segovia. El I8 de marzo de i82o se reunieron por última vez los capitulares, divididos en los linajes de Día Sanz y Fernán García, conquistadores de la villa de Madrid. Al día siguiente tomó posesión el nuevo Ayuntamiento constitucional. En la sesión del 27 de abril fueron numerosos los elogios al sermón que había dado el domingo de ramos D. Santiago Sedeño, canónigo magistral de la catedral y exaltado liberal, y se ordenó la publicación de unos cuantos ejemplares del sermón, que se repartirían por la ciudad ${ }^{16}$.

En lo referente a las escuelas de primeras letras se nombraron nuevos maestros en la escuela de la Compañía, la que controlaba el Ayuntamiento, ya que en la escuela de Hondategui, de patronato privado, no podían intervenir. También, en la sesión de I2 de mayo de I820 se ordenó a los curas que explicasen la Constitución en sus sermones de los domingos, y que esto mismo hiciesen los maestros de escuela, además de facilitar un informe mensual del estado de las escuelas y del progreso en la enseñanza de la Constitución ${ }^{17}$.

Y eso hacían los maestros de todas las escuelas de la capital; enviaban informes mensuales especificando:

- Si cobraban su dotación.

- De dónde salían las rentas para las citadas dotaciones.

- Cuántos alumnos tenían.

- Qué enseñaban en la escuela.

16 AMs, Libro de Acuerdos de la Ciudad AC-II48, folio I89.

17 Ams, Libro de Acuerdos de la Ciudad AC-II48, folios 236-239. 
Los maestros de Hondategui daban su informe del mes de julio de i82r de la siguiente manera ${ }^{18}$.

Los maestros de primeras letras de las piadosas fundaciones del Sr. Hondategui en cumplimiento de superiores órdenes manifiestan a VSS, que a pesar que durante este trimestre ha habido que despedir a casi todos los huérfanos colegiales de este establecimiento por no tener recursos sus Patronos para sostenerlos, ni menos para pagar a los maestros a quienes se están debiendo tres mesadas cumplidas; existen en dicha escuela ciento sesenta y dos niños de los que escriben y estudian los catecismos de Fleuri y Astete 52. Is cuentan y además estudian la Constitución. Y los restantes leen, silabean y aprenden el abecedario. Notándose en los más de ellos bastante buena disposición y en muchos adelantamiento conocido...

Lo mismo hacía el maestro de escribir de la escuela de la Compañía, Gregorio de Cros: «... sigo instruyendo a mis Discípulos cuanto me es posible en la Constitución y Catecismo de la misma como igualmente me está mandado...». La enseñanza del Catecismo Político de la Constitución española era fundamental, y todos los maestros presumían en los exámenes públicos, de realizarla de manera intachable, con notable aprovechamiento de la juventud, aunque luego fuesen acusados de liberales por ello y tuviesen que retractarse de las enseñanzas que habían impartido durante el trienio liberal, como hicieron los maestros de la escuela del convento de San Francisco, frailes, que rápidamente enviaron una carta al nuevo Ayuntamiento realista ${ }^{19}$, junto con un nuevo catecismo.

Los Padres Maestros de esta Escuela caritativa del Convento de N.P.s. Francisco de esta Ciudad cerciorados de las ideas que los niños han aprendido durante el Gobierno constitucional tan perjudiciales al Estado del Rey y de la Religión, y deseosos de desvanecerlas de su memoria e imbuirles las Verdaderas, han determinado instruirles en las obligaciones que comprende el adjunto Catecismo...

Era un orgullo para los maestros y para sus escuelas acudir a los exámenes públicos. En Segovia capital encontramos varias menciones a estas convocatorias. Es cierto que existía cierta rivalidad en las escuelas de la capital, principalmente entre las de Hondategui y la del convento de San Francisco, también gratuita. Los exámenes se realizaban por separado en ambas escuelas y lo habitual era invitar a las máximas autoridades de la ciudad, tanto a nivel civil, militar como eclesiástico, para que pudiesen comprobar el avance en la enseñanza de los niños, dando premios a los que mejor habían aprovechado estas enseñanzas y, al mismo tiempo, reconocían también la labor de los maestros.

En lo relativo al maestro de primeras letras D. Francisco de Frutos Illanas, existe un expediente en el Archivo Municipal de Segovia, fechado en I825, que reza de la siguiente manera: «... para que se le reponga en la Escuela fundada por Ondategui». Consta de varios documentos ${ }^{20}$.

18 AMS, II99-8I.

19 AMS, I2O3-37.

20 AMS, I342-24. 
El primero de ellos, fechado el I2 de agosto de i825, es una carta remitida por D. Francisco de Frutos Illanas, maestro de primeras letras, antiguo profesor de Hondategui y, además, vecino de la ciudad de Segovia. La misiva estaba dirigida nada menos que al rey, a Fernando VII, aunque realmente quien aparece como receptor de la carta es el ministro del Departamento de Gracia y Justicia.

La historia es interesante.

En primer lugar, D. Francisco decía que era maestro de primeras letras, «con título expedido por el Supremo Consejo de Castilla». Fue contratado como tal maestro para la Escuela del Señor Hondategui por los patronos de la fundación en el año I8I8 y estuvo allí hasta I823. También nos cuenta que su comportamiento fue «correcto y honrado» durante el tiempo que estuvo dando clase en la escuela, cuatro años y io meses.

Nos recuerda que la escuela llevaba ya cerrada dos años, desde I823 (ocupación del colegio y escuela por las tropas suizas francesas y españolas que acompañaban a los cien mil hijos de San Luis entre I823 y I826). Sin embargo, el motivo del cierre para este maestro no era otro que la falta de pago del Crédito Público, que no pagaba los intereses a la fundación (la famosa Caja Real de Consolidación y los intereses al 3\% anual). Según él, con lo que debían de años atrasados era posible que «llegase a los dos millones de reales el descubierto de la fundación».

El motivo principal, aparentemente, por el que escribía este memorial era la deuda que decía tener la fundación con él, 4.196 reales, según, siempre sus palabras, los recibos y certificados que tenía, facilitados por uno de los señores patronos, el cura de la parroquia del Salvador.

Pedía este dinero argumentando las numerosas deudas que tenía

... todo el tiempo que está cerrada dicha Escuela estoy perdiendo nueve rreales cada día, para mantener mi muger y tres hijos; y así es Señor que aunque vendí prendas de mi casa, estoy deviendo más de dos mil reales [...] al pronto pido a V.M. una limosna para ayudar de mantener mi familia. Señor, siempre é amado la Religión Christiana A.V.R.M. y a todas las legitimas personas reales...

Una de las conclusiones que podemos sacar de estas palabras es lo referente al salario que tenía como maestro:

Mensual, a 9 reales diarios, 270 reales al mes

Anual, 270 reales por todo el año, en total 3.240 reales

¿Mucho dinero? Probablemente no. Siendo el maestro de leer, su salario anual estaba dentro de lo que se pagaba en ciudades parecidas a Segovia (ninguna se podía comparar a la capital del reino en cuanto a los salarios de los maestros de primeras letras). También es preciso tener en cuenta el nivel salarial que se daba en la ciudad de Segovia en el primer cuarto del siglo xix y su relación con lo que cobraban otros maestros de su misma categoría. Podríamos decir que era un privilegiado si lo comparamos con los salarios que tenían los maestros de las escuelas de las temporalidades, conocidas como la Compañía, que un día sí y otro también solicitaban al Ayuntamiento, que actuaba como patrono, que les aumentasen la 
dotación o que les pagasen las numerosas mesadas que les debían ${ }^{21}$. Y daba igual que las súplicas de los maestros se realizasen durante el trienio liberal o después de i823. Tuvieron poco éxito en sus peticiones. Y es que Segovia, ya desde el siglo anterior, había sido considerada una ciudad bastante cara, donde los alimentos, además de ser difíciles de conseguir, subían de precio con mucha facilidad. Y, para colmo de males, el Ayuntamiento siempre respondía a las solicitudes que no tenía «propios» con los que responder.

El Reglamento de Escuelas de Primeras Letras de I825, en el artículo I67, especificaba lo que podían cobrar los maestros, dependiendo de su categoría y la población en la que estuviesen destinados

- I. $^{\text {a }}$ clase de Madrid.

8.000 reales

- 2. ${ }^{\text {a }}$ clase de Madrid

6.600 reales

- I. $^{\text {a }}$ clase capitales de provincia 5.000 reales

En los primeros años del siglo xIx, el primer maestro o maestro de escribir de la Escuela de Hondategui, D. Domingo Sáez Montejo, tenía un salario anual de 5.475 reales, y el maestro de leer, que no pasante, D. Fco. de Frutos Illanas, llegaba a los 3.240 reales anuales.

El salario del maestro había ido subiendo progresivamente. Sólo hay que recordar los 2.000 reales que señalaba en su testamento de I75I D. Diego Ochoa de Hondategui para el primer maestro de la escuela, Ildefonso Cabañas, más 500 reales de gastos de papel, tinta y otras cosas que tenía que facilitar a los alumnos.

Y, por último, habría que volver a mencionar que, oficialmente la fundación, el Patronato no tenía ingresos, puesto que había tenido que vender todos sus bienes y propiedades, y no cobraba los réditos del dinero que tenía invertido en deuda pública.

De la misiva que D. Francisco envió al Ministerio de Gracia y Justicia, podemos extraer más datos, entre ellos, que el cierre del Colegio y Escuela producido en I8I2 y I8I3 por falta de fondos fue temporal. No sabemos cuánto duró exactamente, pero sabiendo que el maestro fue contratado en I8I8, es probable que en ese momento volviese a funcionar normalmente, de hecho, D. Francisco nos informa que en los años I820 y I82I realizó «exámenes públicos de II3 y IIs niños, con conocida hutilidad».

Al mismo tiempo que mencionaba los exámenes públicos, el maestro Illanas nos daba cuenta del número de alumnos que tuvo esos dos años (o quizá nos da el dato del número de alumnos que hubo en toda la Escuela). Sin embargo, este dato no es fiel reflejo de la realidad. Pienso que en esta época, como en las anteriores, acudían a la Escuela tanto niños pobres, de gracia, catalogados como tal por los administradores y patronos de la fundación (un requisito que aparecerá posteriormente, cuando el control de las escuelas esté en manos de la

${ }_{21}$ Ams, Libro de Acuerdos de la Ciudad AC-II48, folio 189, 27 abril I820. Al maestro de la escuela de leer de la Compañía le rebajan la dotación de 250 ducados anuales a la cantidad de 150 ducados, sólo i.65o reales. 


\section{4 \\ FRANCISCO DE FRUTOS. MAESTRO DE PRIMERAS LETRAS PURIFICADO. SEGOVIA I823 JOSÉ LUIS MANRIQUE SANZ}

municipalidad, será el informe de pobreza, realizado habitualmente por el cura o el párroco) y niños «de pago», que abonaban la cuota mensual establecida, fijada en 4 reales mensuales por alumno ${ }^{22}$.

En I823 el maestro Illanas, una vez cerrada la Escuela por la ocupación de las tropas suizas, francesas y españolas, no se había quedado quieto ${ }^{23}$. Necesitaba mantener a su familia y mientras el asunto de la Escuela Hondategui se solucionaba, abrió su propia escuela, en su casa (es de suponer que los alumnos serían los mismos que iban antes a la fundación, pero me imagino que sólo aceptaría a aquellos alumnos que le dejasen algún emolumento, alguna retribución, es decir, los alumnos de pago). Así, nos relata en el mismo documento:

Señor [Su Majestad], todo el tiempo que está cerrada la Escuela del Sr. Ondategui, la é tenido en mi Casa para ayuda de sostenerme pues no é ganado más de un real y medio a dos reales cada un día...

\section{Y continúa con un asunto novedoso}

Señor, la Escuela la tengo cerrada desde el día 29 de julio por orden del Señor Corregidor, que según Real Orden, me va a purificar, pero se tarda tanto [...] me conceda licencia para volver abrir mi Escuela...

El asunto novedoso es el de la «Purificación». Estamos en I823, ha vuelto al poder Fernando VII, y todo aquello que tuvo algún toque de liberalismo durante el trienio anterior debía ser pasado por el control del Gobierno.

En Segovia había pocos maestros, los de las temporalidades (antiguo colegio de la Compañía), la escuela gratuita del convento de San Francisco y los dos que sabemos que había en la fundación de Hondategui (uno de ellos era Francisco de Frutos Illanas, que actuaba como maestro de la clase de leer y también como él nos ha dicho, como leccionista en su casa).

El primero que sufrió el cambio de régimen fue el maestro de escribir de la escuela de Hondategui, D. Domingo Sáez Montejo, que tachado de «liberal» por enseñar la Constitución, y quizá por defenderla, huyó de la ciudad rumbo a la Corte, donde podía pasar más desapercibido. En el verano de I823, cuando casi nadie conocía las Juntas de purificación, al catedrático de Latinidad en el Seminario Conciliar D. Santiago García ya «... se le ha separado de su destino mediante su adhesión al sistema

22 Esta referencia a los alumnos que pagaban y a los que no ya se realizaba en las escuelas de Costura que abrió la Sociedad Económica Segoviana de Amigos del País en los años 1786 (dentro de la ciudad) y 1788 (en el arrabal), en el que diferenciaban a las niñas en «de pago» y «de número», que debían estar en igual número en cada una de las escuelas.

23 Ams, Libro de Acuerdos AC-II53, folio 84, 4 febrero i823. Los maestros de las escuelas de Hondategui solicitaron al Ayuntamiento que les diese algún auxilio, con calidad de reintegro, pues llevaban I4 meses sin cobrar, y mostraban en su petición «su adhesión al Sistema constitucional». El Ayuntamiento pretendía dar I.50o reales al maestro de escribir, Montejo, y 700 al maestro de leer, Francisco de Frutos, procedentes de la Junta de Nobles Linajes, previo informe del jefe político. Finalmente éste se echó atrás y no les dieron la ayuda solicitada. 
constitucional» ${ }^{24}$, aplicándose la orden de la Junta Provisional de Gobierno de I8 de abril de i823 por la que se daban las reglas para la separación y reposición de los empleados públicos. Poco después, en julio de ese año, se cesó a los maestros de la Compañía, D. Ángel Giménez y D. Gregorio de Cros, y se ordenó la fijación de edictos convocando pretendientes para las dos escuelas de primeras letras, leer y escribir e incluso que el agente que tenía el Ayuntamiento pusiese algunos carteles de dichas vacantes en la Corte ${ }^{25}$. Estos mismos maestros siguieron dando problemas, ya que los que habían ocupado su puesto en las escuelas de la Compañía, D. José Ortea y D. Manuel García Gil, se quejaron a la ciudad diciendo que los alumnos se les iban a otras escuelas «que no están aprobadas». El Ayuntamiento acordó que el alguacil mayor hiciese saber a los maestros Cros y Giménez que tenían que cerrar inmediatamente sus escuelas, «bajo de tomar el Ayuntamiento las medidas más serias» ${ }^{26}$. Solo cuatro días tardaron estos maestros «cesantes» en presentar un memorial sobre el decreto de suspensión de sus escuelas dado por el Ilustre Ayuntamiento. Y la ciudad acordó que «ínterin no resuelva el Supremo Consejo de Castilla sobre este particular continúen suspensos en la enseñanza pública según ya está acordado... $\gg^{27}$. En cuanto a los maestros del convento de San Francisco, fueron cambiados de destino, y uno de ellos terminó dejando los hábitos ${ }^{28}$.

Este afán depurativo de todo lo que hubiese tenido un tinte liberal cesó por un breve periodo de tiempo tras la firma del Real decreto de 26 de octubre de I823 que mandaba suspender las purificaciones de cualquier clase «... hasta que meditado por Mí este negocio en Madrid, recaiga con el acierto que deseo la oportuna determinación», aunque fueron vueltas a instaurar por Real Cédula de I de abril de i824. En relación con el magisterio de primeras letras volvieron a tener vigencia con la real disposición de i6 de julio de $1825^{29}$, por la que todos los maestros de primeras letras que hubiesen obtenido su título antes del 7 de marzo de I82o debían

... presentarse a ser purificados ante la Junta Inspectora de la Provincia a que correspondan sus respectivos domicilios, en el término de dos meses contados desde su publicación: los que fueron examinados durante el Gobierno llamado Constitucional, quedan sujetos a lo dispuesto en la Real Orden de 2 de octubre de i824...

Los maestros sometidos a proceso de purificación debían presentar una nota por duplicado de los pueblos en que habían residido desde el primero de enero de I82o hasta la fecha, designando el tiempo que estuvieron en cada uno, además de los establecimientos de educación que habían tenido a su cargo, «... expresando si han tenido empleo, destino o servido cargo público durante el Gobierno llamado Constitucional o si han sido Milicianos Voluntarios o pertenecido a sociedades reprobadas».

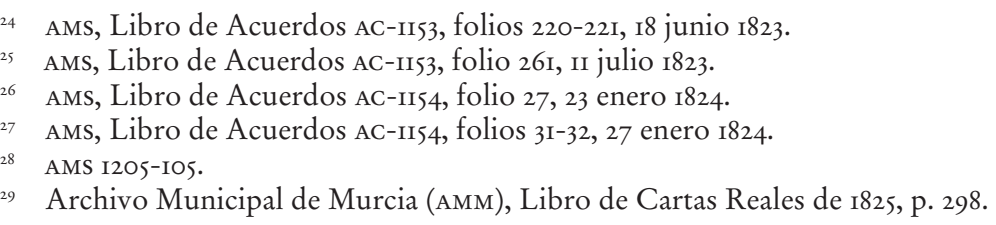


A los maestros que salían «impurificados» se les retenía el título de maestro de primeras letras para que no pudiesen hacer uso de él. A los «purificados» se les devolvía el título «... poniendo en ellos la nota de estarlo, sin la cual ninguna autoridad le permitirá la enseñanza pública ni privada de la juventud en clase de leccionistas...».

En principio quedaban sujetos a purificación los empleados nombrados por el Rey antes del 7 de marzo de 1820 (Francisco de Frutos Illanas no pertenecía a la Administración, ni había sido nombrado por el Rey, sólo tenía el título de maestro de primeras letras, según dice, obtenido del Consejo de Castilla).

Un trabajo realizado por Bartolomé Martínez $z^{30}$ nos informa acerca de la documentación que se requería en los expedientes de purificación:

- Información «de puritate sanguinis», la partida de nacimiento del interesado y de sus padres.

- Información «de vita et moribus», exigía la certificación de buena conducta emitida por parte del párroco y del alcalde mayor.

- Prueba «de sufficientia», se había de pasar ante la Junta elegida por el Colegio Académico. Aquí le examinaban de todos los ramos que comprende la primera enseñanza:

- Doctrina Cristiana

- Aritmética

- Gramática y ortografía castellana

- El arte de leer y escribir

- El arte de enseñar a los niños estos conocimientos por el orden y método más breve y provechoso habiendo formado seis muestras, las cinco de escribir y una de aritmética...

- Investigación sobre «conducta política», que se haría por medio de la Junta de Purificación con el testimonio de tres individuos. Los llamaban «informes reservados».

Este afán y necesidad de «purificarse» parece que no afectó a los maestros de primeras letras de la capital. Sólo uno, D. Domingo Martín de Tejada, que había huido del pueblo de Abades tachado de «liberal» y se había refugiado en la ciudad se quejaba constantemente de que no le permitían tener escuela abierta con la que poder mantenerse e incluso llegó a incoar un recurso ante el Tribunal de Justicia para volver a ejercer el magisterio ${ }^{31}$. El mismo maestro Tejada y otro leccionista, D. Ángel Giménez, solicitaban al Ayuntamiento un año más tarde «... se les exima de la multa de 50 ducados por tener abiertas sus escuelas y declarar no estar comprendidos en la prohibición de la enseñanza pública» ${ }^{32}$.

No sucedió lo mismo con algunos maestros de la provincia que, ya en el otoño de I823, solicitaron ser examinados en la capital, de nuevo, como maestros de

Bartolomé Martínez, B.: «Las purificaciones de maestros de primeras letras y preceptores de Gramática en la reforma de Fernando VII», Historia de la Educación: Revista Interuniversitaria, n. ${ }^{\circ} 2$ (1983), pp. 249-254.

${ }_{31}$ AMS, Libro de Acuerdos AC-II54, folio 84, 2 marzo I824.

32 AMs, Libro de Acuerdos AC-II54, folio 553, 25 junio I825. 
primeras letras. Casi todos consiguieron su objetivo, con las recomendaciones de los examinadores: «...advertimos no estar complemente instruido en ellos; pero mediante a prometer aplicación en lo subcesivo y a que por otra parte escasean maestros de este ramo [...] creemos que puede v.s. concederle poder ejercer dicho Magisterio de primeras letras en dicha Villa, [...] para que por medio de su aplicación pueda obtener el título del Supremo Consejo»33.

Nuestro maestro de primeras letras no las tenía todas consigo, parece que los servicios prestados a la fundación Hondategui no iban a ser suficientes para poder recuperar su condición de maestro (sin afiliación política) y como parecía que no estaba seguro, añadía varios párrafos en la carta que dirigía al monarca, cuando menos curiosos:

I. ... estuve en la Escuela del Sr. Ondategui [...] sin que hablásemos una palabra a favor de la Constitución, porque siempre la aborrecí con mis Potencias y sentidos...

2. ... Señor, no se qué razón, que razón hay para que siendo blanco se me quite tener escuela en mi casa, cuando sufrí un examen y gasté mi dinero para tener este oficio con que poder ganar para mantenerme toda mi vida...

3. ... serví a $v^{a}$.R.P. en el Regimiento de Infantería de la Princesa 6 años a saber desde 1794 asta I8oo con toda honradez, como consta en la Licencia que tengo y que estuve en la Campaña de Francia...

4. ... cuando a esta ciudad de Segovia vino el señor Batanero fue tanto lo que me alegré ver que en la desa [dehesa] tenía a dos pícaros boluntarios constitucionales atados, que del uno dije al señor Batanero lo muy malo que era y que así no le diera libertad. Se fue dicho señor Batanero y vino el Constitucional, por el metieron en la cárcel a varias personas y a mi me la juró diciendo «deja al maestro que yo lo compondré». Tube la fortuna que vino el señor Cura Merino y Tropa francesa, que si no me meten en la cárcel y acaso me hubieran quitado la vida por aquél gran pícaro.

De estos cuatro puntos, no he podido comprobar la veracidad de ninguno. Incluso en el apartado militar no consta ningún dato que certifique que Fco. de Frutos Illanas, natural de Segovia, vecino del barrio del Mercado, nacido en 1776 (nos cuenta que esta carta la escribe cuando tiene 49 años, en I825) hubiese estado en algún Regimiento, según la consulta realizada en los Archivos General Militar de Segovia y en el Archivo General de Simancas.

Quizá no existan datos, o quizá existan y estén desaparecidos o quizá no haya sabido encontrarlos o quizá todo sea una burda patraña, una gran mentira para poder conseguir otra vez su medio de subsistencia y el dinero que se le debían.

Me inclino más por esta última posibilidad. Ya hemos visto que en los informes que mandaban mensualmente certificaban que explicaban el Catecismo de la Constitución con aprovechamiento de los niños. Otro motivo es la frase que incluye D. Francisco en el memorial que envía a Su Majestad, una frase que debía

33 AMS, I2I2-IO9. 
ser bastante común y típica de la época, muy socorrida por muchas personas: «Si V.M. gusta me ponga una ynsinia de Honor, lo estimaré mucho».

Otro de los aspectos que no he podido comprobar es su condición de «blanco». Existe un interesante trabajo de Canal ${ }^{34}$ sobre los «colores» en las guerras civiles españolas. En él, y por lo que atañe a D. Francisco, dice que la oposición entre «blancos»y «negros» se remontaba al trienio liberal (I820-I823) y con mucha frecuencia en los años de la «segunda restauración fernandina» (1823-I833, la década ominosa) para simbolizar el enfrentamiento entre los realistas y los liberales.

«Blancos» serían los realistas y «negros» los liberales. Francisco de Frutos Illanas, en I825, cuando escribía el memorial al Rey, certificaba que era «blanco», y lo confirmaba, lo atestiguaba con el episodio anteriormente referido, ocurrido en la Dehesa de la ciudad, donde se solían realizar los ajusticiamientos.

No quedaba aquí la misiva, no tenía nada que perder y mucho que ganar. Para finalizar, el maestro de primeras letras pedía tres cosas al monarca:

I. Que se le pagase la cantidad que le debía la fundación Hondategui, 4.196 reales.

2. Que si se abriese la citada Escuela de Hondategui, se le pusiera en la plaza que tuvo, sin más oposición.

3. Por último, que si se abriese alguna escuela en la ciudad, «ruego a v.M. mande me pongan por Maestro en ella».

Avanza la tramitación del expediente. Parece que el maestro Illanas continuaba sin estar conforme, y en otra carta escrita un año más tarde, echaba la culpa al corregidor de Segovia de no haber «evacuado» el memorial, por cuya razón «V.M. no me ha hecho Justicia ni Gracia». A la par, nos facilita algún dato acerca de la situación del Patronato de Hondategui, dato que, si no es por este memorial, probablemente desconoceríamos.

El primero de ellos es que el Patronato tenía «ingresos extraordinarios», procedentes de unas casas que tenía en propiedad situadas también en el barrio del Salvador, por las que cobraban un alquiler que «pasa de I.200 reales», según nos cuenta el maestro, mientras que a él para el sustento de su familia no eran capaces de pagarle los 4.000 reales que le debían.

Sin embargo, lo que más le indignaba era la situación de haber tenido cerrada «su escuela», en su casa. Y nos lo explicaba de esta forma:

- Había dos maestros leccionistas «a los que se tiene por negros» que habían sido sometidos a la purificación y no la habían superado, «continúan impurificados y con escuelas en sus Casas», cuando él, que siempre había sido «blanco» tuvo que estar tres meses y medio sin poder ejercer el magisterio en su casa ${ }^{35}$.

34 Canal, J.: «Matar negros y hacer blancos: los colores y los nombres del enemigo en las guerras civiles de la España contemporánea», UNED. Espacio, tiempo y forma. Serie V, Historia Contemporánea, t. 20 (2008), pp. 19-36.

35 Se refiere aquí a los antiguos maestros de la escuela de la Compañía D. Ángel Giménez y D. Gregorio de Cros. 
Por tanto, ya estaba purificado y podía volver a ejercer como maestro «... me hicieron la purificación en Segovia como consta por la certificación de Purificado que tengo y título del Consejo de v.R.M.».

No contento con poder volver a dar clase, continuaba analizando, a su manera, la situación del magisterio de primeras letras en Segovia.

- Había mujeres que en sus escuelas de niñas tenían a muchachos (recordar que no estaba permitida la coeducación de niños y niñas).

- Un «hombre imperfecto y de oficio Cardador» tenía escuela en su Casa y en otras, según dice Illanas, sin tener título del Consejo [de Castilla] de s.M.

- No entendía que un hombre que había estado en presidio tuviese escuela en su Casa, también sin título oficial.

Estas situaciones que denunciaba decía «son deshonra de los profesores que somos y que en esta ciudad de Segovia se consienta lo dicho» ${ }^{36}$.

Pasó otro año más y nuestro persistente maestro Illanas envió otra carta dirigida a Su Majestad, fechada el 8 de septiembre de i827. En ella nos vuelve a contar las mismas cosas que hacía dos años, cuando envió el primer memorial. Algunos términos cambiaban:

- Continuaba teniendo escuela en su casa, ganando de dos a tres reales cada día, por lo que decía «... lo paso mal yo fundamentalmente con mi mujer y tres hijos...».

- Quería, intentaba, pedía y suplicaba que se abriese la Escuela de Hondategui, ya que su salario sería mucho mejor y por eso le decía a s.M. «Señor, hay muchos niños perdiéndose por las calles por estar cerrada esta Escuela tan justamente fundada en misericordia para los pobres».

- Volvía a recordar que tenía el certificado de «purificado».

- Contaba que la Escuela de leer de la Compañía de Segovia se «alla sin maestro». El maestro solicitaba al Rey nada menos que se dirigiese al Ayuntamiento y que dijese a los «... señores de dicha ciudad me ponga en dicha Escuela en premio a mis méritos [...] estimaré hesta Gracia de v.R.M., siempre que dicho Ayuntamiento o Personas que tengan este cargo me paguen corrientemente lo que corresponde a dicha plaza o aunque no sea más que por seis reales diarios».

Con tanta carta y tanto memorial, alguno tenía que llegar a su destino. Y eso sucedió. A finales de septiembre de I827, D. Francisco Tadeo Calomarde, a la sazón ministro de Gracia y Justicia, escribió una carta al corregidor de Segovia para que «... cumpla V. con lo mandado... antes de que se adopten otras providencias por hacerle cumplir las soberanas determinaciones».

36 En los Libros de Acuerdos del Ayuntamiento de Segovia entre los años I823 y I827 no aparece reflejada ninguna de las denuncias que efectúa el maestro Illanas. Tampoco aparece ninguna mención oficial al proceso de purificación de los maestros de primeras letras de la capital. Sin embargo, sí existen muchas peticiones de información de la conducta moral y política de militares, de alta y baja graduación, que habían estado destacados en el Colegio de Artillería situado en el Alcázar de Segovia. 
En este punto, el ministro dejaba todo en manos de otro, del corregidor, mientras que nuestro maestro parecía que tenía muchas esperanzas de conseguir algo fructífero de tanto papel y tinta gastado.

Lo que consiguió fue que el corregidor de Segovia se tomase más en serio su trabajo, y «evacuase», un mes más tarde, un informe dirigido al Excmo. Sr. Ministro de Gracia y Justicia, Tadeo Carlomarde, en relación con la persona de D. Francisco de Frutos Illanas. Nos cuenta esto:

- Fco. de Frutos, maestro de primeras letras, se halla ejerciendo el ministerio en esta ciudad de Segovia, en su casa del barrio del Mercado (en el Arrabal), a la que «concurren más de cincuenta muchachos a leer y escribir y después tiene sus lecciones en casas particulares».

- En cuanto al Patronato Hondategui, «lo primero es el sostenimiento de los niños (el Colegio) y con el superavit se sostenía la Escuela». En esta fecha, I827 $\mathrm{y}$ «desde hace algunos años no existe tal Collegio por falta de fondos y por consiguiente no hay ni ha avido tal Escuela...».

- Respecto a la deuda de 4.000 reales «y más» que solicitaba el maestro, los patronos de dicho Colegio Hondategui, y Escuela, le comunicaron al corregidor que no era así, ya que la deuda sería tal si la Escuela se hubiese mantenido abierta, pero se le ordenó cerrar la Escuela porque no se le podía pagar su salario. Decía el corregidor que para lograr esto, el cierre, «... hubo necesidad de valerse de la autoridad judicial y después para hacerle entregar la llave de dicha Escuela fue necesario valerse de la misma...».

Da la impresión de que nuestro maestro de primeras letras, cuando redactó sus memoriales y los envió al Rey, no contaba toda la verdad, pedía beneficios con mucha confianza y familiaridad. De todo lo que los patronos contaron al corregidor, el maestro no contaba nada.

Sin embargo, también hay que ser cautos con las medias verdades de los patronos de la fundación, ya que omitían la información relativa a la renta que percibían por el alquiler de dos casas que tenían en propiedad, y alguna propiedad más de la que tenemos noticia unos años más tarde, gracias a una Cuenta de Gastos e Ingresos que el administrador D. Luis Tomé de la Infanta tuvo que presentar ante el gobernador civil de la provincia en el año $1833^{37}$. Según este informe, tenían estos ingresos por alquileres:

- Alquiler de una casa ropería en el valle de Alcudia al conde de Bornos, 200 reales/año.

- D. Santos Garay, una casa en el Salvador, 900 reales/año ${ }^{38}$.

- Alquiler de una casa en la calle de las Flores, también en el barrio del Salvador de Segovia, I8o reales/año.

AMs, 76I-19-2.

${ }_{38}$ Esta vivienda fue realizada en el año 1790 para residencia del cura del Salvador, también patrón de las fundaciones. En algunos documentos aparece mencionada como la «casa nueva»; su coste fueron I20.00o reales de vellón, y en la década de I840 fue adquirida por D. Benito González, que la dejaría en herencia a su hijo, el filántropo segoviano D. Ezequiel González de la Bodega. 
En total, I.280 reales. ¡Estaba muy bien informado el maestro cuando daba estas cifras!

Incluso, algunas habitaciones del Colegio las alquilaron como viviendas a particulares, como sucedió con un maestro llamado D. Vicente Barbero, al que también alquilaron la escuela, por medio año, por lo que pagaba la cantidad de I75 reales.

Finalmente, la liquidación de haberes que esperaba D. Francisco de Frutos Illanas, maestro de primeras letras purificado, se produjo, como así lo demuestran los libros, otra Cuenta de Gastos e Ingresos, presentada por el administrador para el año $1834^{39}$, pero ya la percibieron sus herederos

... tres mil doscientos cuarenta y cuatro reales que en virtud de dicho acuerdo y oficio pagué a los herederos del difunto maestro de la Escuela Frutos Illanas, según el adjunto recibo señalado $\mathrm{n}^{\circ}$ 3, pues aunque su deuda eran 4.056 reales, rebajó y perdonó a la fundación el 20 p\% y quedó reducida a dichos 3.244 .

\section{Conclusiones}

El Real Patronato de fundaciones de D. Diego Ochoa de Hondategui tuvo un papel fundamental en la enseñanza gratuita de las primeras letras en la ciudad de Segovia. Sus maestros eran los mejor pagados; sus escuelas, las más numerosas. Sólo para niños.

Al maestro de leer D. Francisco de Frutos Illanas, que obtuvo su puesto al azar, le tocó vivir un periodo un tanto complicado. Por un lado, el Patronato había dejado de cobrar las numerosas rentas de que disponía, se había visto obligado a vender sus bienes e invertir el dinero en la caja del Estado, en la «deuda perpetua», por lo que no percibía los intereses y, por tanto, los maestros no cobraban su dotación. Por otro lado, la irrupción del trienio liberal obligó a los maestros de primeras letras a enseñar el Catecismo Político de la Constitución de I8I2, y éstos demostraban su aplicación y la de sus alumnos, ante toda la ciudad, en la realización de los exámenes públicos. De tal manera que, cuando volvió al poder Fernando VII en I823, todos aquellos que habían mostrado, obligados o no, su adhesión al sistema constitucional fueron cesados de sus empleos y forzados a sufrir un proceso de purificación para recobrar su cargo.

El maestro Illanas fue una de estas personas. Para recuperar el dinero que le debían no dudó en enviar varios memoriales al Rey en los que informaba de la situación económica del Patronato de Hondategui, de lo que sucedía con otros maestros de la ciudad, tenidos por «negros» liberales, mientras que él había sido siempre «blanco» realista. O incluso sobre las personas que ejercían el magisterio sin tener el título adecuado. Algunas de estas verdades del maestro no se pueden demostrar y ni siquiera aparecen reflejadas en los libros de acuerdos de la ciudad.

39 AMS, 76I-I9-2. 
La escuela de Hondategui no se volvió a abrir. D. Francisco de Frutos Illanas, con su título de maestro purificado, continuó impartiendo el magisterio en su casa. El dinero que le debían lo disfrutaron sus herederos.

\section{Bibliografía}

Bartolomé Martínez, B.: «Las purificaciones de maestros de primeras letras y preceptores de Gramática en la reforma de Fernando VII», Historia de la Educación: Revista Interuniversitaria, n. ${ }^{\circ} 2$ (1983), pp. 249-254.

Canal, J.: «Matar negros y hacer blancos: los colores y los nombres del enemigo en las guerras civiles de la España contemporánea», UNED. Espacio, tiempo y forma. Serie v, Historia Contemporánea, t. 20 (2008), pp. 19-36.

Corchado Soriano, M.: «Desamortización frustrada en el siglo xviII», Centro de Estudios de Castilla la Mancha, n. 3 (1972), pp. 87-107.

De Colmenares, D.: Historia de la insigne ciudad de Segovia y compendio de las historias de Castilla. II, Segovia, Academia de Historia y Arte de San Quirce, 1984.

Faubell Zapata, V.: Acción educativa de los Escolapios en España (1733-1845), Madrid, Ed. Instituto Universitario «Domingo Lázaro», I987.

Faubell Zapata, V.: «Los Escolapios en España», Analecta Calasanctiana. n. ${ }^{\circ} 99$ (2008), pp. 57-65.

García SAnz, A.: Desarrollo y crisis del Antiguo Régimen en Castilla la Vieja: economía y sociedad en tierras de Segovia de I500 a I814, Madrid, Ed. Akal Universitaria, 1986.

Jovellanos, G.: Memoria sobre educación pública. Su tratado teórico-práctico de enseñanza con aplicación a las escuelas y colegios de niños, Madrid, BAE, I858.

Laspalas Pérez, J.: «Una alternativa para la educación popular en la España del siglo Xviñ: el método uniforme del Padre Felipe Scio», Revista Española de Pedagogía, año LII, n. ${ }^{\circ}$ I99, septiembre-diciembre (I994), pp. 485-500.

Martínez de Pisón, E.: Segovia: evolución de un paisaje urbano, Madrid, Colegio de Ingenieros de Caminos, Canales y Puertos, 1976.

Resines Llorente, L.: La Catedral de papel. Historia de las Cartillas de Valladolid, Valladolid, Diputación de Valladolid, 2007.

Ruiz Berrio, J.: La educación en España. Textos y documentos, Madrid, Actas Editorial, 1996.

Scio Riaza, F.: Método uniforme para las escuelas de Cartilla, Deletrear, Leer, Escribir, Arithmética, Gramática Castellana y Exercicio de Doctrina Christiana, como se practica por los Padres de las Escuelas Pías, Madrid, Imprenta de Pedro Marín, I780.

Valles Garrido, J. M.: «La distribución de "Sopas Económicas" del Conde Rumford en la Segovia de comienzos del siglo XIX», Estudios Segovianos, Segovia, Ed. Real Academia de $\mathrm{H}^{\mathrm{a}}$ y Arte de San Quirce, n. ${ }^{\circ}$ 92-1995, pp. I43-176.

VICENTE JARA, F.: La enseñanza primaria en Murcia en el siglo XIX (I800-I857), Murcia, Editora Regional de Murcia, 1989. 